\title{
Kontrol Tracking Fuzzy Berbasis Performa Robust Untuk Quadrotor
}

\author{
Dinang Sohendri, Trihastuti Agustinah \\ Jurusan Teknik Elektro, Fakultas Teknologi Industri, Institut Teknologi Sepuluh Nopember (ITS) \\ Kampus ITS Sukolilo, Surabaya 60111 \\ e-mail: trihastuti@elect-eng.its.ac.id, dinangs61@gmail.com
}

\begin{abstract}
Abstrak-Quadrotor merupakan salah satu jenis UAV (Unmanned Aerial Vehicle) yang memiliki 4 buah baling-baling atau propeller. Desain kontrol tracking fuzzy Takagi-Sugeno digunakan untuk mengatur tracking Quadrotor mengikuti sinyal referensi dan kontrol state-feedback untuk mengatur kestabilan Quadrotor. Metode kontrol fuzzy Takagi-Sugeno akan memecahkan permasalahan nonlinearitas dari Quadrotor dengan merepresentasikan dinamika sistem nonlinear menjadi beberapa model linear. Model linear ini diperoleh dari linearisasi dibeberapa titik kerja Quadrotor. Berdasarkan model tersebut, aturan kontrol fuzzy T-S disusun dengan konsep Parallel Distributed Compensation (PDC). Performa tracking $\boldsymbol{H}_{\infty}$ dirancang untuk mencari gain kontroler yang paling sesuai untuk mengatasi gangguan pada sistem. Selanjutnya, persoalan diselesakan dengan pendekatan Linear Matrix Inequality (LMI) sehingga diperoleh gain kontrol berbasis performa $\boldsymbol{H}_{\infty}$. Hasil simulasi menunjukkan bahwa sistem kontrol hasil desain dapat mengatur gerak Quadrotor sesuai lintasan yang diinginkan dengan Integral Absolut Error 0,1149 pada sumbu $X$ dan 0,0617 pada sumbu $Y$. Selain itu, $\infty$-norm dari performa keluaran memiliki tingkat pelemahan kurang dari $\gamma$ ketika gangguan diberikan.
\end{abstract}

Kata Kunci-Fuzzy Takagi-Sugeno, Linear Matrix Inequality, Performa Tracking $\mathrm{H}_{\infty}$, Quadrotor

\section{PENDAHULUAN}

$\mathrm{T}$ EKNOLOGI penerbangan sedang gencar-gencarnya mengembangkan teknologi pesawat tanpa awak Quadrotor atau Unmanned Aerial Vehicle (UAV). Quadrotor ini memiliki 4 buah baling-baling atau propeller dengan konfigurasi menyilang, propeller depan dan belakang berputar searah jarum jam (clockwise) dan propeller kiri dan kanan berputar berlawanan arah jarum jam (counter clockwise). Quadrotor memiliki dua permasalahan yang harus dijaga agar Quadrotor mampu terbang dengan stabil. Masalah pertama yaitu kestabilan sudut roll, pitch dan yaw pada saat terbang dan permasalahan kedua adalah tracking Quadrotor mengikuti sinyal referensi.

Beberapa penelitian terkait Quadrotor seperti pada [1], menjaga kestabilan sudut roll, pitch, dan yaw menggunakan kontroler fuzzy T-S sehingga mampu dipertahankan disekitar nol. Untuk mengatur gerak Quadrotor, [2] menggunakan Continuous Sliding Mode Control untuk bergerak pada lintasan lurus dengan hasil yang gerak yang baik, namun dengan metode tersebut muncul efek chattering. Metode kontrol Adaptif juga diterapkan untuk mengatur gerak Quadrotor, namun masih rentan terhadap gangguan seperti pada [3]. Oleh karena itu harus dipilh metode kontrol yang tepat untuk mengatur gerak Quadrotor seperti pada [4]. Metode kontrol fuzzy T-S digunakan untuk mengatur gerak Quadrotor dengan hasil yang baik dan mampu tahan terhadap gangguan.

Pada penelitian ini kontroler tracking akan didesain dengan metode fuzzy Takagi-Sugeno berbasis performansi tracking $H_{\infty}$. Digunakan teknik pemrograman Linear Matrix Inequality (LMI) untuk mencari solusi dari metode kontrol tersebut. Performa tracking $H_{\infty}$ didesain untuk mempertahankan Quadrotor agar mampu mengatasi gangguan dari luar.

\section{DASAR TEORI}

\section{A. Model Fuzzy Takagi-Sugeno [5]}

Model fuzzy Takagi-Sugeno (T-S) merupakan salah satu pemodelan yang merepresentasikan sistem nonlinear ke dalam beberapa pendekatan sistem linear. Model fuzzy TakagiSugeno akan melakukan pendekatan sistem nonlinear di beberapa daerah kerja, sehingga sistem bisa dikatakan linear pada derah tersebut dan dibobotkan berdasarkan nilai derajat keanggotaannya. Model fuzzy T-S terdiri dari dua aturan IfThen yaitu aturan plant dan aturan kontroler yang dapat dinyatakan dengan (1).

Aturan plant ke- $i$

$$
\begin{aligned}
& \text { If } z_{1} \text { is } M_{i 1} \text { and } z_{2} \text { is } M_{i 2} \ldots \text { and } z_{j} \text { is } M_{i g} \\
& \text { Then } \quad \dot{x}=A_{i} x+B_{i} u \\
& y=C_{i} x+D_{i} u \quad ; i=1,2, \ldots, r
\end{aligned}
$$

dengan $x \in \mathfrak{R}^{n}, u \in \mathfrak{R}^{m}, y \in \mathfrak{R}^{l}, r$ adalah jumlah aturan fuzzy dan $g$ adalah jumlah himpunan $f u z z y$ dalam satu aturan, $M_{i g}$ adalah himpunan fuzzy, dan $z$ adalah variabel premis yang dapat berupa variabel state sistem. Matriks $A, B, C$ dan $D$ adalah matriks konstan yang dimensinya bersesuaian.

Bentuk keseluruhan model fuzzy T-S dapat dinyatakan dalam (2).

$$
\begin{aligned}
& \dot{x}=\sum_{i=1}^{r} m_{i}(z)\left[A_{i} x+B_{i} u\right] \\
& y=\sum_{i=1}^{r} m_{i}(z)\left[C_{i} x+D_{i} u\right]
\end{aligned}
$$

dengan

$$
m(z)=\frac{\mu_{i}(z)}{\sum_{i=1}^{r} \mu_{i}(z)}
$$




$$
\mu_{i}(z)=\prod_{j=1} M_{i j}\left(z_{j}\right)
$$

pembobot $m_{i}(z)$ dan derajat keanggotaan $\mu_{i}(z)$ memiliki sifat sebagai berikut:

$$
\mu_{i} \geq 0 \sum_{i=1}^{r} \mu_{i}(z)>0, \quad i=1,2, \ldots, r
$$

untuk semua $t$.

Model Referensi merupakan salah satu metode untuk membantu plant agar mampu mengkuti trayektori referensi yang didinginkan dengan persamaan (3) [6].

$$
\dot{x}_{r}=A_{r} x_{r}+B_{r} r(t)
$$

dengan $x_{r}(t)$ adalah sinyal referensi, $A_{r}$ adalah matriks stabil asimtotik, $B_{r}$ adalah matriks masukan, dan $r(t)$ adalah masukan referensi yang nilainya terbatas. Dapat diasumsikan nilai $x_{r}(t)$, untuk semua $t>0$, merepresentasikan trayektori yang diinginkan untuk diikuti oleh state plant $x(t)$.

Performansi tracking $H_{\infty}$ yang berkaitan dengan kesalahan tracking $x(t)-x_{r}(t)$ adalah sebagai berikut [7]:

$$
\frac{\sqrt{\int_{0}^{t_{f}}\left\{\left[x(t)-x_{r}(t)\right]^{T} Q\left[x(t)-x_{r}(t)\right]\right\} d t}}{\sqrt{\int_{0}^{t_{f}} \tilde{w}(t)^{T} \tilde{w}(t) d t}} \leq \gamma
$$

atau

$$
\int_{0}^{t_{f}}\left\{\left[x(t)-x_{r}(t)\right]^{T} Q\left[x(t)-x_{r}(t)\right]\right\} d t \leq \gamma^{2} \int_{0}^{t_{f}} \tilde{w}(t)^{T} \tilde{w}(t) d t
$$

dengan $\tilde{w}(t)$ merupakan matriks augmentasi dari $w(t)$ atau gangguan, $r(t)$ adalah masukan referensi, $t_{f}$ adalah waktu akhir, $Q$ adalah matriks pembobot definit positif, dan $\gamma$ adalah tingkat pelemahan. Arti secara fisik dari (5) adalah bahwa semua nilai $\tilde{w}(t)$ pada kesalahan tracking $x(t)-x_{r}(t)$ akan dilemahkan sampai di bawah atau sama dengan tingkat pelemahan $(\gamma)$ yang diinginkan.

Dari aturan plant yang ada dapat disusun aturan kontroler state feedback dengan skema Parallel Distributed Compensation (PDC) [5].

Aturan kontroler ke- $i$

$$
\text { If } z_{1} \text { is } M_{i 1} \text { and } z_{2} \text { is } M_{i 2} \ldots \text { and } z_{j} \text { is } M_{i g}
$$$$
\text { Then } u=-K_{i}\left[x(t)-x_{r}(t)\right] ; i=1,2, \ldots, r
$$

Keluaran dari kontroler fuzzy secara keseluruhan dapat ditulis dengan:

$$
u=-\sum_{i=1}^{r} m_{i}(z) K_{i}\left[x(t)-x_{r}(t)\right]
$$

dengan memasukkan (7) ke (2) maka didapatkan bentuk keseluruhan sistem lup tertutup sebagai berikut:

$$
\begin{aligned}
\dot{x}(t) & =\sum_{i=1}^{2} \sum_{j=1}^{2} h_{i}\left(x_{z}(t)\right) h_{j}\left(x_{z}(t)\right)\left[\left(A_{i}+B_{i} K_{j}\right) x(t)\right. \\
& \left.-B_{i} K_{j} x_{r}(t)\right]+w(t)
\end{aligned}
$$

dengan mengkombinasiakn (8) dan (5), maka didapatkan Augmented Fuzzy System seperti pada (9).

$$
\dot{x}(t)=\sum_{i=1}^{2} \sum_{j=1}^{2} h_{i}\left(x_{z}(t)\right) h_{j}\left(x_{z}(t)\right)\left[\tilde{A}_{i j} \tilde{x}(t)+\tilde{E} \tilde{w}(t)\right]
$$

dengan

$$
\begin{aligned}
& \tilde{A}_{i j}=\left[\begin{array}{cc}
A_{i}+B_{i} K_{j} & -B_{i} K_{j} \\
0 & A_{r}
\end{array}\right], \quad \tilde{E}=\left[\begin{array}{cc}
I & 0 \\
0 & B_{r}
\end{array}\right] \\
& \tilde{x}(t)=\left[\begin{array}{c}
x(t) \\
x_{r}(t)
\end{array}\right], \quad \tilde{w}(t)=\left[\begin{array}{l}
w(t) \\
r(t)
\end{array}\right]
\end{aligned}
$$

Performa tracking $H_{\infty}$ memiliki persamaan (5), namun jika kondisi awal dipertimbangkan maka dapat dimodifikasi menjadi seperti berikut:

$$
\begin{aligned}
& \int_{0}^{t_{f}}\left\{\left[x(t)-x_{r}(t)\right]^{T} Q\left[x(t)-x_{r}(t)\right]\right\} d t=\int_{0}^{t_{f}} \tilde{x}(t)^{T} \tilde{Q} \tilde{x}(t) d t \\
& \leq \tilde{x}(0)^{T} \tilde{P} \tilde{x}(0)+\gamma^{2} \int_{0}^{t_{f}} \tilde{w}(t)^{T} \tilde{w}(t) d t
\end{aligned}
$$

dengan $\tilde{P}$ adalah matriks pembobot definit positif dan

$$
\tilde{Q}=\left[\begin{array}{cc}
Q & -Q \\
-Q & Q
\end{array}\right]
$$

\section{B. Kontrol Tracking $H_{\infty}$}

Perancangan dari sistem kontrol ini bertujuan untuk menentukan kontroler fuzzy dalam (2) untuk AFS (9) dengan performa tracking $H_{\infty}$ dalam (10) terpenuhi untuk semua $\widetilde{w}(t)$. Selain itu sistem lup tertutup (12) stabil kuadratik.

$$
\dot{x}=\sum_{i=1}^{2} \sum_{j=1}^{2} h_{i}\left(x_{z}(t)\right) h_{j}\left(x_{z}(t)\right) \tilde{A}_{i j} \tilde{x}(t)
$$

Dipilih fungsi kandidat Lyapunov untuk AFS (9) adalah sebagai berikut:

$$
V(\tilde{x})=\tilde{x}^{T} \tilde{P} \tilde{x}
$$

dengan matriks pembobot $\tilde{P}=\tilde{P}^{T}>0$. Derivatif dari $V(\tilde{x})$ adalah

$$
\dot{V}(\tilde{x})=\tilde{x}^{T} \tilde{P} \tilde{x}+\tilde{x}^{T} \tilde{P} \dot{\tilde{x}}
$$

dengan mensubstitusikan AFS (3.40) ke (3.45) maka diperoleh

$$
\begin{gathered}
\dot{V}(\tilde{x})=\sum_{i=1}^{2} \sum_{j=1}^{2} h_{i}\left(x_{z}(t)\right) h_{j}\left(x_{z}(t)\right)\left[\left(\tilde{A}_{i j} \tilde{x}(t)+\tilde{E} \tilde{w}(t)\right)^{T} \tilde{P} \tilde{x}(t)\right. \\
+\tilde{x}(t)^{T} \tilde{P}\left(\tilde{A}_{i j} \tilde{x}(t)+\tilde{E} \tilde{w}(t)\right) \\
\dot{V}(\tilde{x})=\sum_{i=1}^{2} \sum_{j=1}^{2} h_{i}\left(x_{z}(t)\right) h_{j}\left(x_{z}(t)\right)\left\{\tilde{x}(t)^{T}\left(\tilde{A}_{i j}{ }^{T} \tilde{P}+\tilde{P} \tilde{A}_{i j}\right) \tilde{x}(t)\right\} \\
+\tilde{w}(t)^{T} \tilde{E}^{T} \tilde{P} \tilde{x}(x)+\tilde{x}(t)^{T} \tilde{P} \tilde{E} \tilde{w}(t)
\end{gathered}
$$

Solusi umum (9) dengan $\tilde{P}=\widetilde{P}^{T}>0$ adalah petidaksamaan (16) untuk $i=j=1,2$ sehingga performa tracking $H_{\infty}$ dalam (10) terjamin untuk nilai $\gamma$ [7]. 


$$
\tilde{A}_{i j}{ }^{T} \tilde{P}+\tilde{P} \tilde{A}_{i j}+\frac{1}{\gamma^{2}} \tilde{P} \tilde{E} \tilde{E}^{T} \tilde{P}+\tilde{Q}<0
$$

Performa tracking $H_{\infty}$ terbaik dicari dengan formulasi minimisasi berikut:

$$
\min _{\widetilde{P}} \gamma^{2},
$$

$$
\text { dengan syarat }-\tilde{P}>0
$$

Untuk mendapatkan solusi umum $\tilde{P}>0$ dari persoalan minimisasi (17) tidak mudah, sehingga perlu diubah kedalam bentuk Linear Matrix Inequality [8].

Untuk kemudahan dalam perancangan, didefinisikan

$$
\tilde{P}=\left[\begin{array}{cc}
P_{11} & 0 \\
0 & P_{22}
\end{array}\right]
$$

dengan mensubstitusikan (18) ke dalam (16) didapatkan

$$
\begin{aligned}
& {\left[\begin{array}{cc}
A_{i}+B_{i} K_{j} & -B_{i} K_{j} \\
0 & A_{r}
\end{array}\right]^{T}\left[\begin{array}{cc}
P_{11} & 0 \\
0 & P_{22}
\end{array}\right]} \\
& +\left[\begin{array}{cc}
P_{11} & 0 \\
0 & P_{22}
\end{array}\right]\left[\begin{array}{cc}
A_{i}+B_{i} K_{j} & -B_{i} K_{j} \\
0 & A_{r}
\end{array}\right] \\
& +\frac{1}{\gamma^{2}}\left[\begin{array}{cc}
P_{11} & 0 \\
0 & P_{22}
\end{array}\right]\left[\begin{array}{cc}
I & 0 \\
0 & B_{r}
\end{array}\right]\left[\begin{array}{cc}
I & 0 \\
0 & B_{r}
\end{array}\right]^{T}\left[\begin{array}{cc}
P_{11} & 0 \\
0 & P_{22}
\end{array}\right] \\
& +\left[\begin{array}{cc}
Q & -Q \\
-Q & Q
\end{array}\right]<0
\end{aligned}
$$

Pertidaksamaan (19) dapat disederhanakan secara ringkas seperti berikut:

$$
\left[\begin{array}{ll}
S_{11} & S_{12} \\
S_{21} & S_{22}
\end{array}\right]<0
$$

dengan

$$
\begin{aligned}
& S_{11}=\left(A_{i}+B_{i} K_{j}\right)^{T} P_{11}+P_{11}\left(A_{i}+B_{i} K_{j}\right)+\frac{1}{\gamma^{2}} P_{11} P_{11}+Q \\
& S_{12}=S_{21}{ }^{T}=-P_{11} B_{i} K_{j}-Q \\
& S_{22}=A_{r}{ }^{T} P_{22}+P_{22} A_{r}+\frac{1}{\gamma^{2}} P_{22} B_{r} B_{r}{ }^{T} P_{22}+Q
\end{aligned}
$$

Melalui metode Schur Complement, (20) ekuivalen dengan persamaan LMI berikut:

$$
\left[\begin{array}{ccc}
H_{11} & H_{12} & 0 \\
H_{21} & H_{22} & P_{22} B_{r} \\
0 & B_{r}^{T} P_{22} & -\gamma^{2} I
\end{array}\right]
$$

dengan

$$
\begin{aligned}
& H_{11}=\left(A_{i}+B_{i} K_{j}\right)^{T} P_{11}+P_{11}\left(A_{i}+B_{i} K_{j}\right)+\frac{1}{\gamma^{2}} P_{11} P_{11}+Q \\
& H_{12}=H_{21}{ }^{T}=-P_{11} B_{i} K_{j}-Q \\
& H_{22}=A_{r}{ }^{T} P_{22}+P_{22} A_{r}+Q
\end{aligned}
$$

Solusi $P_{11}, P_{22}$ dan $K_{j}$ dari (21) dapat diselesaikan dengan dua tahap. Pertama, dicari $P_{1 l}$ dan $K_{j}$ dengan meminimumkan $H_{1 l}$, kemudian dimasukkan kedalam (21) untuk mendapatkan $P_{22}$.
Langkah pertama yaitu solusi dari $H_{11}<0$

$$
\left(A_{i}+B_{i} K_{j}\right)^{T} P_{11}+P_{11}\left(A_{i}+B_{i} K_{j}\right)+\frac{1}{\gamma^{2}} P_{11} P_{11}+Q<0
$$

dengan $Y_{11}=P_{11}^{-1}$ dan $X_{j}=K_{j} Y_{11}$, (22) ekuivalen dengan

$$
Y_{11} A_{i}^{T}+A_{i} Y_{11}+B_{i} X_{j}+\left(B_{i} X_{j}\right)^{T}+\frac{1}{\gamma^{2}} I+Y_{11} Q Y_{11}<0
$$

Melalui Schur Complement, (23) dapat diubah kedalam bentuk LMI sebagai berikut:

$$
\left[\begin{array}{cc}
Y_{11} A_{i}{ }^{T}+A_{i} Y_{11}+B_{i} X_{j}+\left(B_{i} X_{j}\right)^{T}+\frac{1}{\gamma^{2}} I & Y_{11} \\
Y_{11} & -Q^{-1}
\end{array}\right]<0(24)
$$

Parameter $Y_{l l}$ dan $X_{j}$ dapat diperoleh dengan menyelesaikan persoalan LMI (24).

Langkah kedua yaitu melakukan substitusi $P_{11}$ dan $K_{j}$ ke dalam (21) sehingga berubah ke dalam bentuk LMI standar. Dengan cara yang sama (21) diselesaikan dan didapatkan solusi $P_{22}$. Performa tracking $H_{\infty}$ terjamin untuk tingkat pelemahan $\gamma$ jika didapatkan solusi $P_{11}$ dan $P_{22}$ memiliki nilai definit positif yang memenuhi (16).

$$
\min _{P_{11}, P_{22}} \gamma^{2}
$$

$$
\begin{aligned}
& \text { dengan syarat }-P_{11}=P_{11}{ }^{T}>0 \\
& \text { - } P_{22}=P_{22}{ }^{T}>0 \\
& \text { - (21) }
\end{aligned}
$$

Berdasarkan analisis yang telah dilakukan, kontrol tracking fuzzy berbasis performa robust dapat disusun berdasarkan langkah-langah berikut:

\section{Prosedur Desain:}

1. Tentukan fungsi keanggotaan dan susun aturan fuzzy pada (1).

2. Berikan tingkat pemelemahan awal $\gamma^{2}$.

3. Selesaikan (24) untuk mendapatkan $Y_{1 l}$ dan $X_{j}\left(P_{1 l}\right.$ dan $K_{j}$ juga didapatkan).

4. Substitusi $P_{11}$ dan $K_{j}$ ke dalam (21) kemudian selesaikan untuk mendapatkan $P_{22}$.

5. Turunkan tingkat pelemahan $\gamma^{2}$ dan ulangi langkah 3-5 sampai solusi $P_{11}$ dan $P_{22}$ tidak definit positif.

6. Susun kontroler fuzzy (7)

\section{PERANCANGAN SISTEM}

\section{A. Model Matematika Quadrotor}

Dalam menganalisa dan desain kontroler, sebuah plant harus dibawa kedalam bentuk persamaan state space, sehingga dimungkinkan untuk melakukan linearisasi hingga penyusunan kontroler. Quadrotor memiliki persamaan model seperti pada (25) [9]. 


$$
\left[\begin{array}{c}
\dot{X} \\
\ddot{X} \\
\dot{Y} \\
\ddot{Y} \\
\dot{Z} \\
\ddot{Z} \\
\dot{\phi} \\
\ddot{\phi} \\
\dot{\theta} \\
\ddot{\theta} \\
\dot{\psi} \\
\ddot{\psi}
\end{array}\right]=\left[\begin{array}{c}
\dot{x}_{1} \\
\dot{x}_{2} \\
\dot{x}_{3} \\
\dot{x}_{4} \\
\dot{x}_{5} \\
\dot{x}_{6} \\
\dot{x}_{7} \\
\dot{x}_{8} \\
\dot{x}_{9} \\
\dot{x}_{10} \\
\dot{x}_{11} \\
\dot{x}_{12}
\end{array}\right]=\left[\begin{array}{c}
x_{2} \\
x_{4} \\
\left(s_{x 11} s_{x 7}+c_{x 11} s_{x 9} c_{x 7}\right) U_{1} / m \\
\left(-c_{x 11} s_{x 7}+s_{x 11} s_{x 9} c_{x 7}\right) U_{1} / m \\
x_{6} \\
-g+\left(c_{x 9} c_{x 7}\right) U_{1} / m \\
x_{8} \\
\left.\left(\left(J_{y y}-J_{z z}\right) x_{10} x_{12}+U_{2} l\right) / J_{x x}\right) \\
x_{10} \\
\left.\left(\left(J_{x x}-J_{y y}\right) x_{8} x_{12}+U_{3} l\right) / J_{y y}+U_{4} d\right) / J_{z z} \\
x_{12}
\end{array}\right]
$$

Pada penelitian ini parameter yang digunakan adalah parameter Qball-X4. Parameter ini digunakan sebagai acuan penyusunan kontroler dan simulasi. Nilai parameter Qball-X4 dapat dinyatakan pada Tabel 1.

Tabel 1.

Nilai Parameter Quadrotor [10]

\begin{tabular}{|c|l|c|l|}
\hline No & \multicolumn{1}{|c|}{ Parameter } & Simbol & \multicolumn{1}{|c|}{ Nilai } \\
\hline 1 & Massa & $m$ & $3,499 \mathrm{~kg}$ \\
\hline 2 & Gravitasi & $g$ & $9,81 \mathrm{~kg} / \mathrm{m}^{2}$ \\
\hline 3 & Momen Inersia pada sumbu X & $J x x$ & $0,03 \mathrm{~kg} \cdot \mathrm{m}^{2}$ \\
\hline 4 & Momen Inersia pada sumbu Y & $J y y$ & $0,03 \mathrm{~kg} \cdot \mathrm{m}^{2}$ \\
\hline 5 & Momen Inersia pada sumbu Z & $J z z$ & $0,04 \mathrm{~kg} \cdot \mathrm{m}^{2}$ \\
\hline 6 & Jarak rotor dari pusat massa & $l$ & $0,2 \mathrm{~m}$ \\
\hline 7 & Gaya drag & $d$ & $3,13 \times 10^{-5}$ \\
\hline 8 & Gaya thrust & $b$ & $7,5 \times 10^{-7}$ \\
\hline 9 & Bandwith aktuator & $\omega$ & $15 \mathrm{rad} / \mathrm{s}$ \\
\hline 10 & Konstanta gaya dorong & $K$ & $120 \mathrm{~N}$ \\
\hline
\end{tabular}

\section{B. Linearisasi}

Persamaan (25) merupakan sistem nonlinear, sehingga perlu dilakukan linearisasi untuk dapat menerapkan kontrol linear yang akan dirancang. Linearisasi akan dilakukan menggunakan metode linearisasi jacobian, dengan daerah kerja disekitar titik ekuilibriumnya. Dengan daerah kerja sistem seperti pada Tabel 2, didapatkan sistem hasil linearisasi seperti pada (30-33).

Tabel 2.

Daerah Linearisasi $\phi$ dan $\theta$

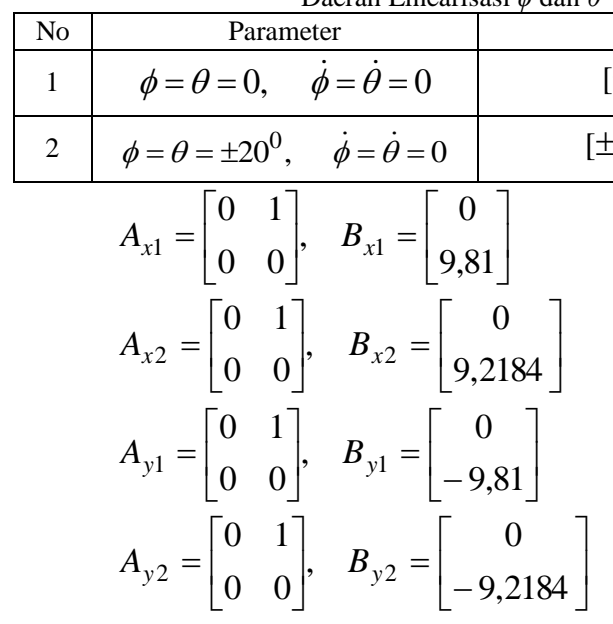

Berdasarkan skema PDC, dapat disusun aturan kontroler fuzzy yang bersesuaian dengan aturan plant (30-33) sebagai berikut:

aturan kontroler untuk gerak $X$

Aturan kontroler ke-1:

$$
\begin{aligned}
& \text { If } \left.\quad x_{9} \text { is } M_{1} \text { (sekitar } 0 \mathrm{rad}\right) \\
& \text { Then } \quad \theta=K_{x 1}\left[x-x_{r}\right]
\end{aligned}
$$

Aturan kontroler ke-2:

$$
\begin{aligned}
& \text { If } \quad x_{9} \text { is } M_{2}( \pm p i / 9 \mathrm{rad}) \\
& \text { Then } \quad \theta=K_{x_{2}}\left[x-x_{r}\right]
\end{aligned}
$$

aturan kontroler untuk gerak $Y$

Aturan kontroler ke-1:

$$
\begin{aligned}
& \text { If } \quad x_{7} \text { is } M_{1} \text { (sekitar 0 rad) } \\
& \text { Then } \quad \phi=K_{y 1}\left[x-x_{r}\right]
\end{aligned}
$$

Aturan kontroler ke-2:

$$
\begin{aligned}
& \text { If } \quad x_{7} \text { is } M_{2}( \pm p i / 9 \mathrm{rad}) \\
& \text { Then } \quad \phi=K_{y_{2}}\left[x-x_{r}\right]
\end{aligned}
$$

\section{Parameter Kontroler}

Model Referensi untuk sistem seperti pada (38)

$$
A_{r}=\left[\begin{array}{cc}
0 & 1 \\
-8,5 & -7
\end{array}\right], \quad B_{r}=\left[\begin{array}{c}
0 \\
8,5
\end{array}\right]
$$

Pembobot Q seperti (39) dan pelemahan optimal $\gamma=0.85$.

$$
Q=10^{-1} \times\left[\begin{array}{cc}
4,8 & 0 \\
0 & 1,8
\end{array}\right]
$$

Dengan menggunakan LMI Toolbox pada Matlab, didapatkan parameter kontroler seperti berikut.

$$
\begin{aligned}
K_{x 1} & =\left[\begin{array}{ll}
-1,2448 & -0,7130
\end{array}\right] \\
K_{x 2} & =\left[\begin{array}{ll}
-1,3247 & -0,7588
\end{array}\right] \\
K_{y 1} & =\left[\begin{array}{ll}
1,2448 & 0,7130
\end{array}\right] \\
K_{y 2} & =\left[\begin{array}{ll}
1,3247 & 0,7588
\end{array}\right] \\
P_{x 1} & =\left[\begin{array}{ll}
1,5730 & 0,5745 \\
0,5745 & 0,3371
\end{array}\right] \quad P_{x 2}=\left[\begin{array}{ll}
0,7483 & 0,3977 \\
0,3977 & 0,3537
\end{array}\right] \\
P_{y 1} & =\left[\begin{array}{ll}
1,5730 & 0,5745 \\
0,5745 & 0,3371
\end{array}\right] \quad P_{y 2}=\left[\begin{array}{ll}
0,7483 & 0,3977 \\
0,3977 & 0,3537
\end{array}\right]
\end{aligned}
$$

Sistem kontrol yang dirancang memiliki arsitektur seperti pada Gambar 1.

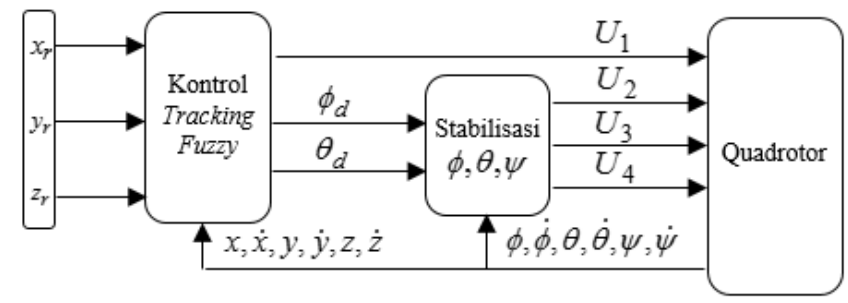

Gambar 1. Arsitektur Sistem Kontrol untuk Quadrotor 


\section{HASIL SIMULASI}

Simulasi dilakukan dengan menggunakan arsitektur kontrol seperti pada Gambar 1 untuk gerak Quadrotor pada sumbu $X$ dan $Y$. Hasil dari simulasi dapat dilihat pada Gambar 2-4.

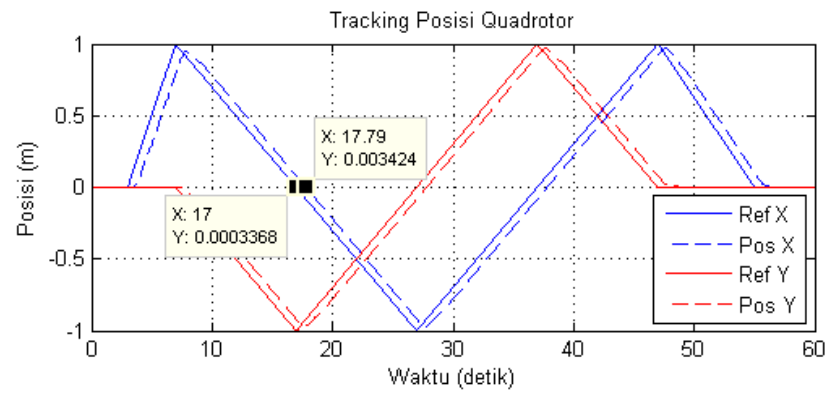

Gambar 2. Tracking Posisi Quadrotor

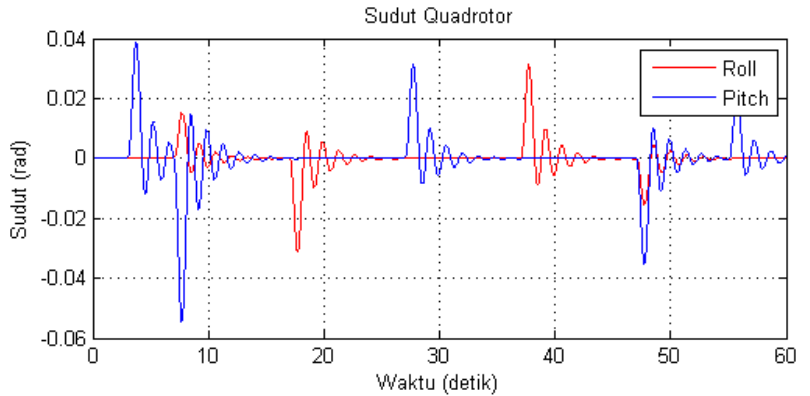

Gambar 3. Sudut Roll dan Pitch untuk Gerak Quadrotor

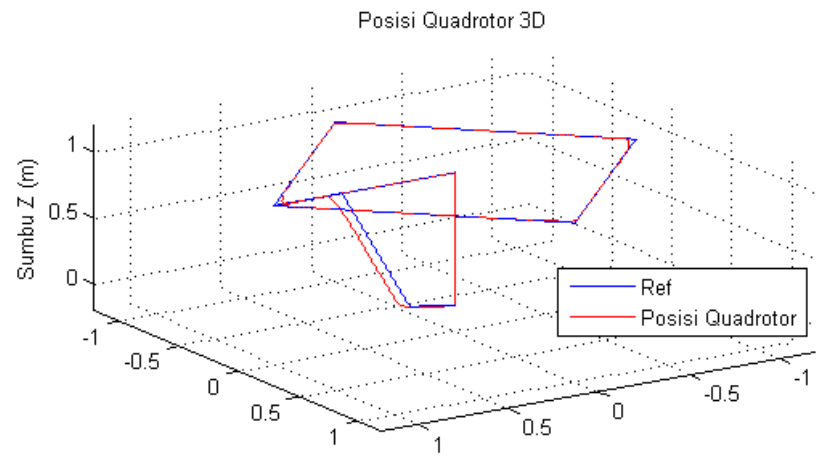

(c)

Gambar 4. Plot 3D Hasil Simulasi

Dari hasil simulasi dapat diketahui bahwa Quadrotor mampu bergerak mengikuti referensi tracking yang diinginkan dengan perubahan sudut roll dan pitch tidak terlalu besar. Hal ini menunjukkan bahwa Quadrotor dapat bergerak dengan stabil dengan Integral Absolute Error (IAE) 0,1149 pada sumbu $X$ dan 0,06171 pada sumbu $Y$. Akan tetapi gerak tersebut memiliki osilasi di awal gerak dan muncul beda fasa selama 0,79 detik.

Untuk menguji ketahanan sistem kontrol yang dirancang maka dilakukan simulasi sistem kontrol dengan pemberian gangguan. Gangguan hembusan angin diberikan pada plant posisi $X$ dan plant posisi $Y$ yang diibaratkan dengan sinyal pulsa dengan besar $2 \mathrm{~N}$ atau $0,5716 \mathrm{~m} / \mathrm{s}^{2}$ selama lima detik. Pemberian gangguan diuji dengan variasi gamma seperti pada Tabel 3 sehingga dapat diketahui gamma yang paling optimal.
Tabel 3.

Nilai Gain State-Feedback dan $\infty$-norm Sistem dengan $\gamma$ yang Berbeda-beda

\begin{tabular}{cccccc}
\hline \hline$\gamma$ & \multicolumn{2}{c}{$K_{x 1}$} & \multicolumn{2}{c}{$K_{x 2}$} & $\left\|T_{z, w}(s)\right\|=\gamma^{*}$ \\
\hline 0,9 & {$[-1,1678$} & $-0,6751]$ & {$[-1,2428$} & $-0,7184]$ & 0,8535 \\
0,85 & {$[-1,2448$} & $-0,7130]$ & {$[-1,3247$} & $-0,7588]$ & 0,8007 \\
0,8 & {$[-1,3371$} & $-0,7572]$ & {$[-1,4229$} & $-0,8058]$ & 0,7454 \\
0,7 & {$[-1,6935$} & $-0,9303]$ & {$[-1,8022$} & $-0,9900]$ & 0,5883 \\
\hline \hline
\end{tabular}

Pada sumbu $X$ gerak Quadrotor mengalami sedikit pergeseran dari lintasan awal, pada detik ke 15 posisi qudrotor bergeser sehingga muncul deviasi posisi sekitar 0,06 meter. Variasi $\gamma$ berpengaruh pada besar deviasi kesalahan posisi Quadrotor, dengan deviasi terkecil ketika nilai $\gamma=0,7$ seperti pada Gambar 6. Untuk melihat jumlah error posisi Quadrotor pada sumbu $X$ dapat dilihat pada Tabel 4. Ketika gangguan diberikan pada detik ke 15, muncul kesalahan posisi Quadrotor sampai detik ke 20 ketika gangguan sudah hilang.

Dapat dilihat pada Gambar 7, pada detik ke 15 gangguan diberikan pada plant $X$, sinyal kontrol $U 3$ berubah sebesar $0,5 \mathrm{~N}$. Sinyal kontrol berkurang sebesar $0,5 \mathrm{~N}$ untuk mengatasi pergeseran posisi $X$. Posisi gerak Quadrotor dijaga disekitar lintasan gerak dan ketika gangguan sudah hilang maka posisi kembali pada lintasan yang diinginkan.

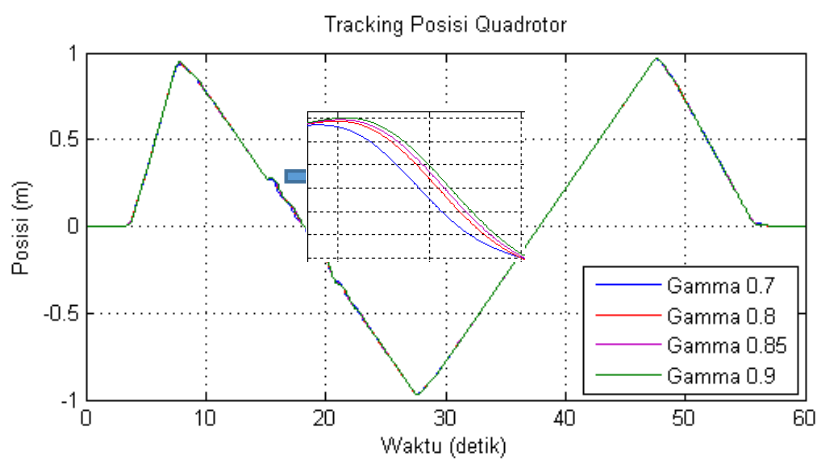

Gambar 5. Perbandingan Posisi Quadrotor dengan Variasi $\gamma$

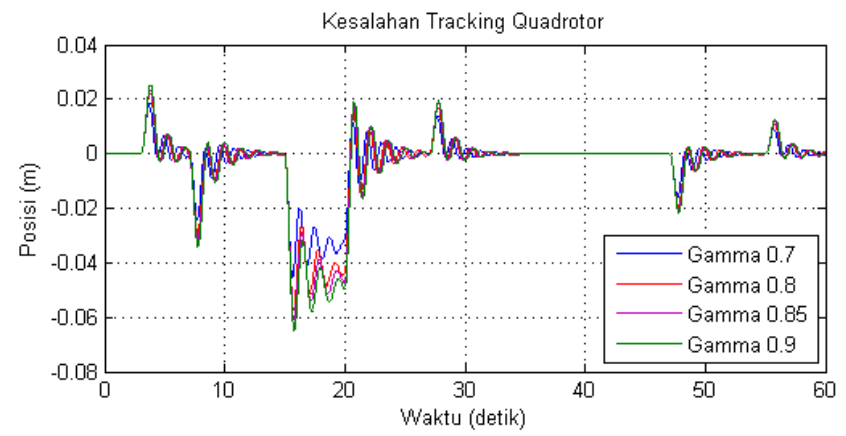

Gambar 6. Kesalahan Posisi $X$ 


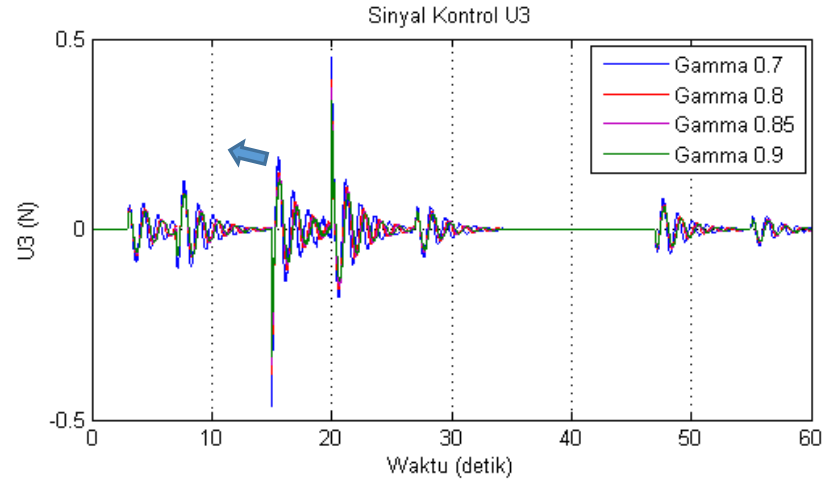

Gambar 7. Sinyal Kontrol $U 3$ untuk Gerak Sumbu $X$

Tabel 4.

Kesalahan Posisi Quadrotor pada Sumbu $X$ dengan Berbagai Nilai $\gamma$

\begin{tabular}{ccc}
\hline \hline$\gamma$ & Error & IAE \\
\hline 0,9 & $\pm 0,065$ & 0,3976 \\
0,85 & $\pm 0,061$ & 0,3729 \\
0,8 & $\pm 0,057$ & 0,3459 \\
0,7 & $\pm 0,045$ & 0,2701 \\
\hline \hline
\end{tabular}

Tabel 5.

Nilai Gain State-Feedback dan $\infty$-norm Sistem dengan $\gamma$ yang Berbeda-beda

\begin{tabular}{cccccc}
\hline \hline$\gamma$ & \multicolumn{2}{c}{$K_{y 1}$} & \multicolumn{2}{c}{$K_{y 2}$} & $\left\|T_{z, w}(s)\right\|=\gamma^{*}$ \\
\hline 0,9 & {$[-1,1678$} & $-0,6751]$ & {$[-1,2428$} & $-0,7184]$ & 0,8535 \\
0,85 & {$[-1,2448$} & $-0,7130]$ & {$[-1,3247$} & $-0,7588]$ & 0,8007 \\
0,8 & {$[-1,3371$} & $-0,7572]$ & {$[-1,4229$} & $-0,8058]$ & 0,7454 \\
0,7 & {$[-1,6935$} & $-0,9303]$ & {$[-1,8022$} & $-0,9900]$ & 0,5883 \\
\hline \hline
\end{tabular}

Pengaruh yang sama juga terjadi pada sumbu $Y$. Plant posisi $Y$ diberi gangguan dengan nilai $\gamma$ divariasikan $0,9,0,85,0,8$, dan 0,7. Hasil yang diperoleh gain state-feedback $K_{y 1}, K_{y 2}$ dan $\infty$-norm untuk nilai $\gamma$ yang berbeda-beda dapat dilihat pada Tabel 5.

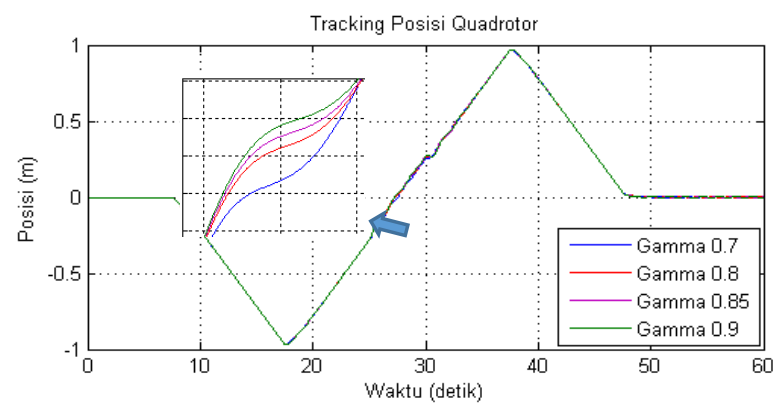

Gambar 8. Perbandingan Posisi Quadrotor dengan Variasi $\gamma$

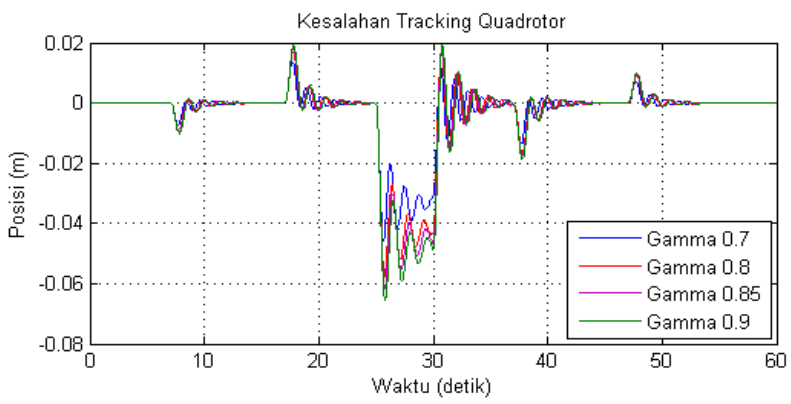

Gambar 9. Kesalahan Posisi $Y$

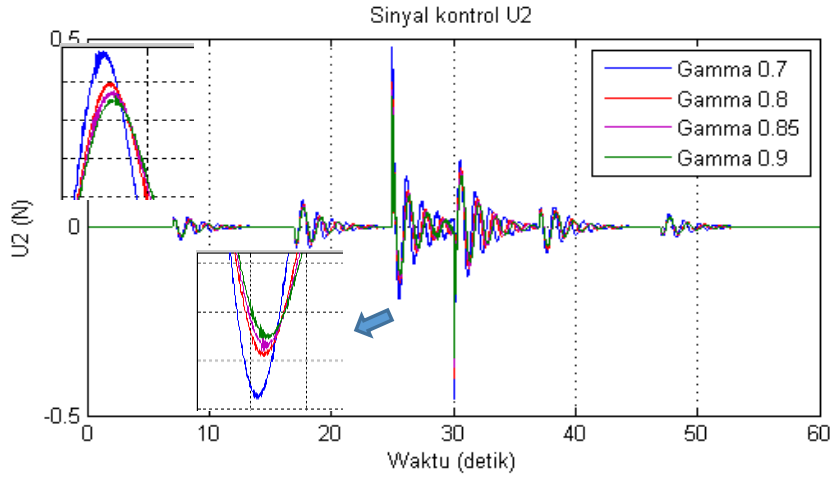

Gambar 10. Sinyal Kontrol $U 2$ untuk Gerak Sumbu $Y$

Pada detik ke 25, posisi $Y$ mengalami pergeseran sehingga mempunyai deviasi posisi sekitar 0,06 meter seperti pada Gambar 9. Deviasi ini muncul selama gangguan tetap diberikan. Variasi $\gamma$ yang diberikan mempengaruhi nilai error posisi $Y$ dengan nilai deviasi terkecil pada $\gamma=0,7$. Pada Tabel 6 dapat dilihat dengan $\gamma=0,7$ memiliki nilai error dan IAE terkecil, sehingga $\gamma=0,7$ merupakan level pelemahan optimal. Sinyal kontrol $U 2$ bertambah $0,5 \mathrm{~N}$ untuk mengatasi pergeseran posisi $Y$.

Tabel 6.

Kesalahan Posisi Quadrotor pada Sumbu Y dengan Berbagai nilai $\gamma$

\begin{tabular}{ccc}
\hline \hline$\gamma$ & Error & $I A E$ \\
\hline 0,9 & $\pm 0,065$ & 0,3976 \\
0,85 & $\pm 0,061$ & 0,3729 \\
0,8 & $\pm 0,057$ & 0,3459 \\
0,7 & $\pm 0,045$ & 0,2701 \\
\hline \hline
\end{tabular}

Dari hasil simulasi tersebut kesalahan posisi terkecil baik pada sumbu $X$ atau sumbu $Y$ terjadi ketika nilai $\gamma=0,7$. Pada level pelemahan tersebut posisi Quadrotor dijaga dengan kokoh disekitar lintasan geraknya. Oleh karena itu dapat disimpulkan bahwa sistem yang telah dirancang terbukti robust terhadap ganggan dari luar.

\section{KESIMPULAN}

Metode kontrol fuzzy Takagi-Sugeno bekerja dengan baik untuk mengendalikan gerak Quadrotor mengikuti lintasan yang diinginkan dengan nilai Integral Absolute Error (IAE) 0,1149 pada sumbu $X$ dan 0,06171 pada sumbu $Y$. Kontrol tracking fuzzy yang dirancang memiliki performa robust dengan performa keluaran dibandingkan dengan tingkat pelemahan gangguan kurang dari sama dengan tingkat pelemahan $\gamma$ yang ditentukan. Hal ini menunjukkan bahwa ketika gangguan diberikan, kontroler mampu mereduksi pengaruh yang muncul sehingga performa keluaran dari sistem masih sesuai dengan yang diinginkan.

\section{DAFTAR PUSTAKA}

[1] Wang, Hanghao dan Wang, Mao, "Robust Fuzzy Variable Structure Control of T-S Model for a Quadrotor Unmanned Air Vehicle", International Journal of Multimedia and Ubiquitous Engineering, China, 2015. 
[2] Fang, Zhuo dkk., "Feedback Linearization and Continuous Sliding Mode Control for a Quadrotor UAV", Proceedings of the 27th Chinese Control Conference, China, 2008.

[3] Razinkova, Anastasia dkk., "Adaptive Control over Quadcopter UAV under Disturbances", International Conference on Control, Automation and Systems (ICCAS 2014), Korea, 2014.

[4] Lee, Hyeonbeom dan Kim, H. J., "Robust Control of a Quadrotor using Takagi-Sugeno Fuzzy Model and an LMI Approach", International Conference on Control, Automation and Systems (ICCAS 2014), Korea, 2014.

[5] Tanaka, Kazuo. dan Wang H. O., "Fuzzy Control System Design and Analysis", John Wiley \&Sons, Inc., 2001

[6] Ogata, Katsuhiko, "Modern Control Engineering 3rd edition", Prentice-Hall, New Jersey, 1997.

[7] Zhou, Kemin, "Essentials of Robust Control", Prentice-Hall, New Jersey, May 1999.

[8] Boyd, Stephen, El Ghaoui, L., Feron, Eric, dan Balakrishnan, V., "Linear Matrix Inequality in System and Control Theory", SIAM, Philadelphia, 1994

[9] Tommaso Bresciani, "Modelling, Identification and Control of a Quadrotor Helicopter". Thesis, Department of Automatic Control Lund University, 2008.

[10] Quanser Consulting Inc, "Quanser Qball-X4", Document Number 888.Revision:2, Inovative Educate, Quanser, 2012. 